\title{
Violão: aspectos acústicos, estruturais e históricos
}

\author{
Guitar: acoustic, structural and historical aspects
}

\author{
Monicky E. Zaczéski ${ }^{1}$, Carlos H. Beckert ${ }^{1,2}$, Thales G. Barros ${ }^{1}$, Ana L. Ferreira ${ }^{3}$, Thiago C. Freitas*1 \\ ${ }^{1}$ Universidade Federal do Paraná, Curso Superior de Tecnologia em Luteria, Curitiba, PR, Brasil \\ ${ }^{2}$ Beckert Luteria, Curitiba, PR, Brasil \\ ${ }^{3}$ Universidade Tecnológica Federal do Paraná, Curso de Engenharia Mecânica, Câmpus Guarapuava, Guarapuava, PR, Brasil
}

Recebido em 15 de Junho, 2017. Revisado em 06 de Julho, 2017. Aceito em 10 de Julho, 2017.

\begin{abstract}
Neste artigo será feita uma discussão sobre alguns dos principais aspectos de funcionamento do violão, iniciando por um breve histórico contextualizando as mudanças pelas quais o instrumento passou ao longo dos séculos, incluindo alguns apontamentos feitos pelo físico Michael Kasha. Será dada ênfase na descrição do leque harmônico do violão, um conjunto de barras e travessas que possui finalidades acústicas e estruturais, e que apresentou uma evolução em forma e complexidade que acompanhou o desenvolvimento do violão. É feito um tratamento matemático do ressonador de Helmholtz formado pelo ar enclausurado pelo corpo do instrumento. Por fim, é feita uma discussão sobre os captadores magnéticos, os quais foram introduzidos no violão na primeira metade do séc. XX, visando um aumento do nível de intensidade sonora e, posteriormente levaram ao surgimento dos instrumentos de corpo sólido, como a guitarra e o baixo elétricos.
\end{abstract}

Palavras-chave: física e música, cordas, violão, leque harmônico, captador magnético, acústica.

In this article there will be developed a discussion about some of the main aspects of the functioning of the acoustic guitars, beginning with a brief history putting in context the changes the instrument has been through the centuries, including some notes made by the physicist Michael Kasha. Emphasis will be placed on the description of the guitar bracing, a set of bars and tone braces that have acoustic and structural purposes and that presented an evolution in form and complexity that accompanied the development of the guitar. A mathematical treatment is made of the Helmholtz resonator formed by the air enclosed by the instrument's body. Finally, a discussion is developed about magnetic pickups, which were introduced in the first half of the 20th century to the guitars, with the objective to obtain a higher sound intensity level and later led to the emerging of solid body instruments such as the electric guitar and the electric bass.

Keywords: physics and music, strings, acoustic guitars, guitar bracing, magnetic pickups, acoustics.

\section{Introdução}

O violão é um instrumento musical da família dos cordófonos que possui seis ordens de cordas simples [1], cujo corpo acústico lembra o formato de número oito. Sendo que uma ordem simples corresponde a uma única corda e, uma ordem dupld ${ }^{1}$ corresponde a um par de cordas, geralmente afinadas em intervalo de uníssono ou de oitava justa. Ele traz em sua história diversas teorias sobre a sua origem, dentre as mais difundidas estão a de que descende da kithara grega (uma espécie de harpa), dada a semelhança com a palavra espanhola guitarra mas, também existe a hipótese de que o instrumento seja um sucessor do alaúde.

Porém, o físico-químico Michael Kasha (1920-2013), o qual possuia amplo interesse no violão e em outros instrumentos musicais [2, realizou uma série de pesquisas [3] na década de 1960, concluindo que tais teorias

\footnotetext{
*Endereço de correspondência: tcf@ufpr.br

${ }^{1}$ Popularmente, utiliza-se apenas de corda para ordem simples e ordem para designar a ordem dupla.
}

não possuem evidências válidas. Kasha aponta que a semelhança entre as palavras não vem a ser de fato uma evidência e que seria difícil imaginar a transformação de uma harpa de colo, ou mesmo do alaúde - que possui como características principais o corpo no formato de uma pera, braço curto e um grande ângulo na caixa de cravelhas - em um violão ou em algum parente próximo. No entanto, ele apontou para a possibilidade de que o caminho foi inverso, o violão poderia ter influenciado no desenvolvimento do alaúde, acrescentando trastes ao instrumento levado pelos mouros à Espanha na Idade Média.

Sloane 44 indica que além do alaúde, os árabes trouxeram para a Europa uma espécie de violão primitivo que possuía quatro cordas tocadas com plectro - uma espécie de 'unha' de marfim, osso, etc., com que se fazem vibrar as cordas de certos instrumentos [5] - sendo seu corpo menor que o do violão moderno. Este instrumento tinha como particularidade possuir as curvas superior e inferior do mesmo tamanho, com o contorno do corpo (silhueta) em formanto de número oito. 
Segundo Kasha [3], tanto o nome quanto o design dos violões modernos possuem grande influência de um instrumento persa: o chartar, que conta com quatro ordens simples e uma caixa de ressonância com cintura acentuada. Ao chegar na Europa, o chartar teve mudanças na aparência e no número de cordas. No começo da Renascença, a guitarra com quatro ordens de cordas duplas se tornou dominante na Europa, mas logo depois foi desbancada por uma parente italiana, a guitarra battente, que possuía cinco ordens duplas, afinadas nas notas lá, ré, sol, si e $m i$, do grave para o agudo, que é a mesma afinação das cinco primeiras ordens que virão a se padronizar no violão moderno. Existem diversas guitarras renascentistas dessa época que foram modificadas para que suportassem mais um par de cordas.

A referência mais antiga a uma guitarra de seis cordas [6] aparece em um anúncio de venda de um jornal de Madri do ano de 1760, mencionada como vihuela, palavra usada como sinônimo de guitarra na linguagem espanhola do século XVII em diante. Em tradução livre, o anúncio do Diario noticioso universal de 3 de junho de 1760, nos traz o seguinte: 'Na rua de Atocha, casa do Granadino, vende-se uma vihuela com 6 ordens, feita por suas próprias mãos, boa para acompanhamento....

A guitarra mais antiga [6] 7], com mais de cinco ordens simples que ainda se mantém preservada, é a de Francisco Sanguineo, que foi construída em Sevilha, Espanha, no ano de 1759. Uma vez que este instrumento foi modificado, não se pode afirmar o seu número exato de cordas, porém sabe-se que eram no mínimo seis. Esse antepassado do violão possuia um comprimento de corda vibrante de 670 $\mathrm{mm}$ e, uma estrutura interna no seu tampo, em forma de um leque harmônico simples, o qual era constituído por três barras de madeira dispostas longitudinalmente.

Em 1832, Louis Panormo construiu um instrumento muito próximo ao que conhecemos hoje como violão clássico, embora seja menor e tenha uma cintura mais acentuada. Em 1859, o luthier ${ }^{2}$ espanhol Antonio de Torres Jurado criou o instrumento que atualmente acabou se definindo como o violão clássico 8]. As principais modificações introduzidas por Torres foram: aumento do tamanho da caixa acústica, modificações das proporções, modificações do reforço interno do tampo em forma de leque (com sete barras longitudinais dispostas simetricamente) e a definição do comprimento de escala em $650 \mathrm{~mm}$. Essa combinação de modificações fez o violão ganhar mais adeptos, tendo em vista que a sua capacidade de projeção sonora aumentou consideravelmente, o que fez com que o instrumento 'Torres' passasse a ser considerado o modelo padrão do violão moderno.

Mesmo o violão sendo um instrumento amplamente inserido na cultura musical brasileira, apenas algumas obras discutem a sua importância na identidade e cultura

\footnotetext{
${ }^{2}$ Luteria é a atividade profissional de manufatura, manutenção e restauração de instrumentos musicais de corda, mas, que para alguns autores também inclui atividade com instrumentos de sopro em madeira e o cravo. Luthier, luthière no feminino, é o/a profissional que exerce esta ocupação.
}

nacional 9 11]. O seu uso para atividades de ensino de física é explorado em algumas obras, mas ainda restam muitas abordagens que podem ser exploradas nesse tema. Dentre elas, destacam-se o uso do violão para o ensino de conceitos de física ondulatória por Santos et al. $[12$ e também por Coelho et al. [13, o ensino de acústica através do violão e de um protótipo por Moura e Neto [14, e as propostas do uso do violão no ensino de Física do grupo de Grillo et al. 15, 16. Este artigo, também não vai abarcar todas as abordagens ou temáticas envolvendo física e ensino através do violão, mas dará ao leitor algumas outras possibilidades de conhecer o funcionamento do violão, através de uma descrição do instrumento a partir da Física e da Luteria combinadas.

\section{O violão: aspectos estruturais e acústicos}

\subsection{Estrutura geral do violão}

O violão é um instrumento musical, da família dos cordófonos compostos dedilhados, por possuir mais de uma corda, as quais são colocadas em movimento usando dedos, unhas, plectros ou palhetas [17.

O instrumento possui seis ordens de cordas simples com comprimento acústico de $65,0 \mathrm{~cm} 12$ entre a pestana e o rastilho, afinadas geralmente nas notas $m i_{2}, l a_{2}$, $r e_{3}, s o l_{3}, s i_{3}$ e $m i_{4}$ com frequências $f=82 \mathrm{~Hz}, 110 \mathrm{~Hz}$, $147 \mathrm{~Hz}, 196 \mathrm{~Hz}, 247 \mathrm{~Hz}$ e $330 \mathrm{~Hz}$, respectivamente 18, usando como referência o diapasão de $440 \mathrm{~Hz}$, podendo ainda haver inúmeras outras afinações 19. Trata-se de um instrumento versátil pois, pela quantidade de cordas, suas notas e disposições, permite tanto a execução da melodia, da harmonia ou de ambas em peças mais elaboradas. Existem algumas variantes do violão [20,21], dentre as quais podem-se destacar o violão clássico, o violão flamenco (destinado a música homônima), o violão jumbo (corpo de dimensões maiores que o violão clássico) e, o violão de sete cordas (uma corda mais grave afinada em dó ou ré) [22]. Apesar das diferenças, o elementos constituintes destes instrumentos são os mesmos, salvo alterações e detalhes característicos de cada um.

As principais partes do violão são mostradas nas figuras 1 e 2 e, na sequência as funções associadas a cada uma delas junto aos principais materiais utilizados serão descritas. De maneira geral, o corpo do violão transforma a onda transversal da corda em uma onda longitudinal irradiada pelo instrumento, através do ar, até o ouvinte 12,23. Para que isso ocorra, são necessárias inúmeras partes com funções e ações bem definidas, começando pelo elemento gerador de som: as cordas, que podem ser de nylon ou aço [18] (podendo ocorrer somente com cordas de nylon ou de aço, ou ainda, ambas em conjunto em um mesmo instrumento), que aplicam uma tensão considerável no instrumento, podendo ultrapassar $500 \mathrm{~N}$. 


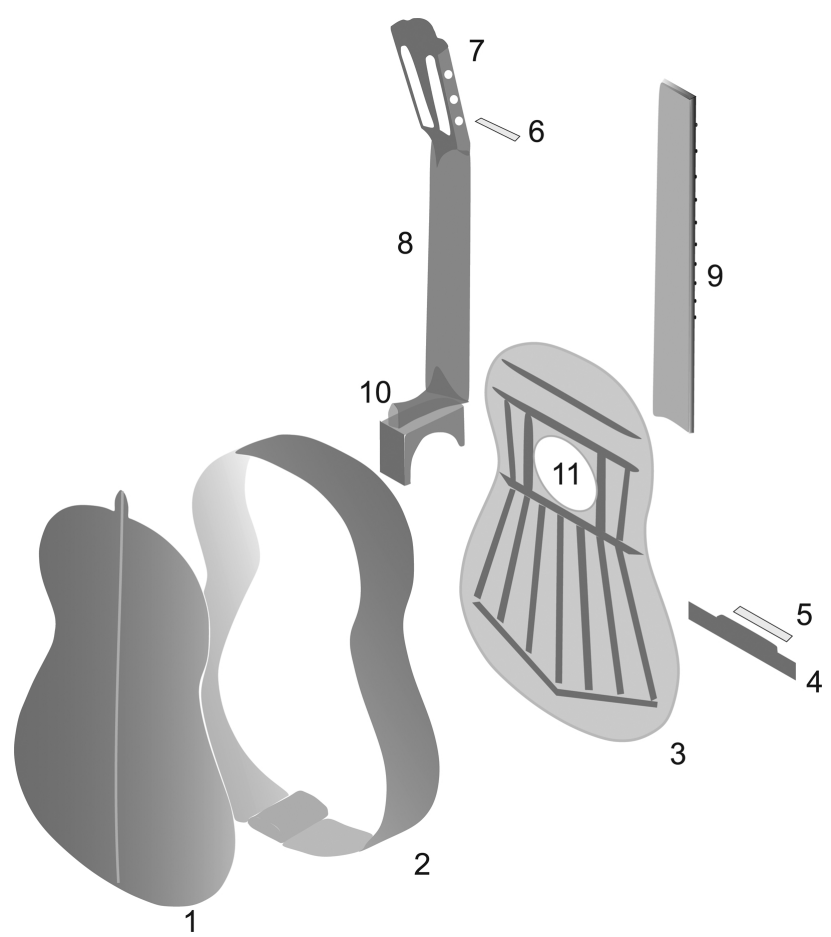

Figura 1: Visão explodida do violão sem as cordas. As partes indicadas são: 1 fundo, 2 laterais, 3 tampo, 4 cavalete, 5 rastilho, 6 pestana, 7 mão, 8 braço, 9 escala, 10 salto e 11 boca. As funções de cada uma das partes indicadas são discutidas no texto.

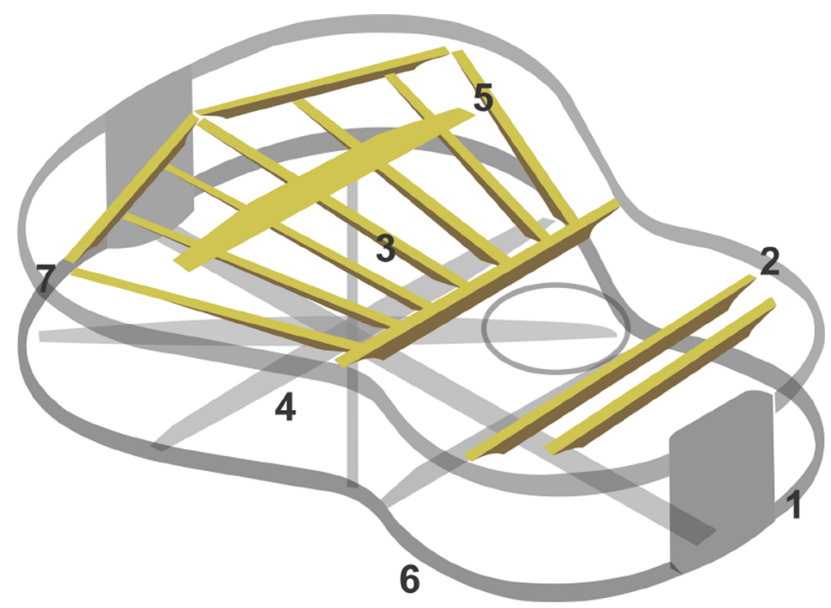

Figura 2: Visão da estrutura interna do violão na ausência do tampo, fundo e laterais. As partes indicadas são: 1 taco, 2 barras transversais, 3 barras longitudinais, 4 estrutura de barras do fundo, 5 contracavalete, 6 contrafaixa e $\mathbf{7}$ barras de fechamento. $O$ leque da estrutura em questão é o modelo Torres. As funções de cada uma das partes indicadas são discutidas no texto.

O comprimento vibrante das cordas é definido pela distância entre a pestana e o rastilho [12], que são duas pequenas barras, feitas geralmente de marfim, osso ou polímeros sintéticos. A pestana se localiza no braço do violão e possui pequenos canais para o assentamento e distribuição uniforme das cordas na largura da escala, já o rastilho encontra-se no cavalete 22 e possui uma forma geométrica complexa 24], permitindo que algumas cordas tenham maior ou menor comprimento, visando garantir a afinação das diversas notas tocadas em cada corda [18. O rastilho também é responsável pela transmissão da vibração das cordas para o cavalete, que consiste de uma peça de madeira colada sobre o tampo e tem por função suportar o rastilho, atuar na transmissão da vibração das cordas para o tampo 23] e sustentá-las. Geralmente o cavalete é confeccionado em diferentes tipos de jacarandá, como o da bahia e o indiano (Dalbergia nigra e, Dalbergia latifolia) 25, 26.

O tensionamento das cordas se dá através das tarraxas, que consistem de um sistema de eixos e engrenagens fixos na mão do violão, permitindo aumentar ou diminuir e, por fim, fixar a tensão aplicada individualmente em cada corda 27. Desta forma, a variação da tensão aplicada nas cordas permite fixar diretamente a frequência fundamental da nota emitida pela corda solta, conforme a eq. (1), que relaciona a frequência $f$ com a tensão aplicada $T$, o comprimento $\ell$ e, a densidade linear $\mu$ da corda.

$$
f=\frac{1}{2 \ell} \sqrt{\frac{T}{\mu}} .
$$

Na mão, encontra-se uma lâmina de madeira, chamada de pala, que além da função estética, atua como reforço estrutural na região da emenda entre a mão e o braço. A pala é geralmente confeccionada com a mesma madeira das laterais e do fundo do instrumento. A mão é em geral da mesma madeira que a usada no braço, por exemplo, cedro rosa (Cedrela fissilis, Cedrela odorata) ou maple (Acer macrophyllum) entre outros 26.

A ligação entre o corpo e a mão do instrumento é feita pelo braço 24], ambos geralmente são confeccionado com madeiras como o cedro rosa, maple ou, mogno (Swietenia macrophylla) [26]. Uma outra função desta parte do violão é sustentar a escala, parte esta que consiste de uma faixa de madeira dura e densa como o ébano (Diospyros ebenum), colada sobre o braço, na qual são fixados os trastes e onde se faz a digitação das notas 4]. Os trastes, que são filetes de metal fixados na escala, tem a função de possibilitar ao músico a digitação das notas através de intervalos bem definidos 16]. Estes intervalos são de um semi-tom temperado [28], o que equivale a passar, por exemplo, da nota dó para a nota dół, quando o comprimento $\ell$ da corda é diminuído de tamanho por uma casa ${ }^{3}$ ou, da nota sí para a nota síb quando o comprimento é aumentado de uma casa. Do ponto de vista da frequência da nota tocada [16, 18, diminuir o comprimento $\ell$ da corda por uma casa equivale a multiplicar a frequência da nota de partida por $\sqrt[12]{2} \mathrm{e}$, aumentar o comprimento $\ell$ da corda por mesma quantidade resulta em nota com frequência da nota de partida dividida pela mesma quantidade.

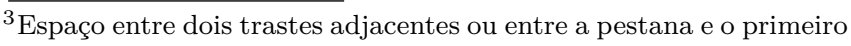
traste.
} 
A partir dessa descrição, percebe-se a importância de que o posicionamento dos trastes seja preciso para que as notas emitidas possuam as frequências corretas. A partir da eq. (1), considerando apenas a dependência da frequência com o comprimento da corda tem-se $f \propto$ $\ell^{-1}$. Para que a frequência aumente o correspondente a mudança de um semitom $(f \rightarrow \sqrt[12]{2} f)$, o comprimento precisa diminuir seguindo $\ell \rightarrow \frac{\ell}{\sqrt[12]{2}}$. A posição $X_{n}$ do $n$-ésimo traste na escala, a partir da pestana, para $n \geq$ 1 , é dada por

$$
X_{n}=\ell-\ell\left[\frac{1}{\sqrt[12]{2}}\right]^{n} .
$$

O formato de número oito do corpo do violão é dado através das laterais, ou faixas, que possuem uma curvatura, obtida através do uso de calor e umidade [24,25 29]. Como as laterais são pouco espessas $(1,6 \mathrm{~mm}-1,8 \mathrm{~mm})$, são utilizadas faixas de madeira, eventualmente serrilhadas, para aumentar a área de colagem entre as laterais e o fundo e as laterais e o tampo, às quais dá-se o nome de contrafaixas 24]. Da mesma forma, os tacos internos, localizados nas emendas das laterais (taco superior para o que fica próximo a junção com o braço e inferior para o que fica na extremidade oposta), visam oferecer maior resistência e robustez ao instrumento e, aumentar a área de colagem entre as laterais. O salto 30], continuidade do braço oferece sustentação deste com relação ao corpo, ampliando também a área de colagem com a parte das laterais em que entra em contato [31]. Em um instrumento com um salto do tipo espanhol, o taco interno superior, o salto e braço são uma só peça, onde as laterais se encaixam [4].

Os frisos e filetes são tiras e lâminas de madeiras diversas, que contornam o instrumento, acompanhando o formato do corpo [24], além de serem elementos decorativos, eles destinam-se a proteger o instrumento de impactos mecânicos, em uma região onde choques podem levar a formação de amplas rachaduras na direção da fibra da madeira [31. Além de madeiras diversas, os frisos podem conter adornos em madrepérola, marfim ou osso 32]. No tampo do instrumento existe uma abertura circular, denominada de boca, que tem a função de acoplar o ar do interior do corpo do instrumento com o meio externo, ela é também responsável por parte da irradiação de som do instrumento [33, conforme vai ser descrito na seção que trata do ressonador de Helmholz e o violão. Ao redor da boca encontra-se um ornamento, denominado roseta, o qual como os frisos também possui função de promover reforço mecânico em uma região naturalmente mais frágil do instrumento. A roseta e o formato da mão são os elementos do violão onde o luthier possui mais liberdade para a criação artística.

O tampo do violão, geralmente confeccionado em abeto (Picea excelsa, Picea sitchense, Picea engelmannii), é uma das partes mais importantes no processo de irradiação de som no instrumento. A descrição, mesmo que simplificada, dos seus modos de vibração e acoplamento com o corpo seria demasiado extensa para este trabalho, sendo que remetemos o leitor interessado as referências 34 35 35 para uma abordagem mais técnica ou, referência [36] para uma versão mais descritiva. Como o cavalete encontra-se acoplado ao tampo através de colagem, o último acaba por ser o elemento responsável pela sustentação de toda a tensão promovida pelas cordas, distribuindo-a pelas demais partes do corpo 37]. Assim, faz-se necessária uma estrutura interna de barras harmônicas que promove o reforço estrutural do tampo - o qual possui em média $5 \mathrm{~mm}$ de espessura 24 - e também alterações mecânicas na flexibilidade do mesmo, as quais compõem, juntas a outras partes, a estrutura do leque harmônico [4], o qual será tratado na seção seguinte, dada a sua importância para o instrumento. Já o fundo do violão, fecha a caixa de ressonância, delimitando o volume de ar contido dentro do instrumento, atuando também na reflexão de ondas sonoras no interior da caixa, tendo papel na projeção do som. Geralmente é construído a partir de jacarandá, maple, mogno e cipreste (Cupressus macrocarpa) [24]. As travessas são estruturas coladas ao fundo do instrumento, com a função de promover reforço estrutural e manter a curvatura do fundo [38], sendo geralmente de abeto, cedro rosa ou mogno.

\subsection{Leque harmônico}

\subsubsection{Funções do leque harmônico}

A área do tampo do instrumento onde se assenta o cavalete, que inicia-se logo abaixo da boca e vai até a extremidade do tampo, contornada pela curva inferior, funciona como um diafragma durante a emissão de som pelo violão. Para suportar a tensão exercida pelas cordas e minimizar as eventuais deformações devido a variações climáticas, existe o leque harmônico, que é um conjunto de barras coladas no lado interno do tampo, conforme mostra a figura 2 Sloane [4] descreve a funcionalidade do leque em também acoplar os movimentos desta superfície, de forma que o tampo possua modos de vibração com certas características.

Sendo o tampo solto considerado um oscilador, o número, frequência, forma e amplitude dos modos normais criados, depende primariamente das propriedades elásticas do material, da forma, massa, espessura, rigidez e, atenuação do som. As barras modificam principalmente os valores de massa e rigidez, o que altera as propriedades elásticas do tampo e, consequentemente o regime de oscilação [4].

A estrutura do tampo de um violão deve ter um equilíbrio entre flexibilidade e rigidez. O tampo deve ser reforçado o bastante para resistir à tensão sem grandes deformações e continuar flexível o bastante para responder as vibrações transmitidas pelas cordas [39]. A parte mais importante do leque é constituída pelo arranjo de uma série de barras longitudinais normalmente dispostas em forma de leque (divergindo a partir da cintura do instrumento), existem ainda duas ou três barras conhecidas como barras harmônicas ou travessas 
que atravessam o tampo no sentido transversal acima e logo abaixo da boca [29]. Segundo Meyer [37. o leque mais adequado para a produção de som é aquele em que as barras longitudinais encontram-se separadas por distâncias uniformes. Existem porém pesquisadores que defendem a utilização de um sistema assimétrico e radial, de acordo com Kasha 40], o leque radial poderia aumentar a amplitude dos movimentos produzidos pelo tampo, e consequentemente a projeção sonora e o tempo de ressonância.

\subsubsection{Características dos leques}

Nesta seção são apresentadas e discutidas as principais características $\bigsqcup^{4}$ encontradas na maioria dos leques harmônicos de violão. Algumas outras abordagens podem agrupar estas propriedades de maneira diferente, mas, para efeitos deste artigo, este será o conjunto de características consideradas mais importantes. A nomenclatura foi adaptada do trabalho do luthier Daniel Friederich [38].

Aberto/fechado: Alguns leques possuem duas barras diagonais que lembram o formato da letra $\mathrm{V}$ ao final das barras longitudinais, estes leques são denominados fechados. Aqueles que não possuem estas barras são abertos.

Assimétrico/dissimétrico/simétrico: $O$ leque simétrico é completamente idêntico em ambos os lados do tampo. O leque dissimétrico possui simetria visual, porém apresenta diferenças, por exemplo, na altura das barras. O leque assimétrico apresenta diferenças na disposição das barras ao compararmos as metades do tampo.

Inteiro/quebrado: o leque inteiro tem as suas barras longitudinais percorrendo a superfície abaixo do cavalete, passando pelo contracavalete (se houver). No leque quebrado as barras são interrompidas ao passarem pela área onde se assenta o cavalete.

Em forma de leque/Em forma de X/ Em disposição radial: Em forma de leque quando as barras têm seu inicio logo abaixo da cintura do instrumento e divergem a medida que se aproximam da extremidade do tampo. Em forma de X quando existem duas barras que se cruzam logo abaixo da boca do instrumento. Em disposição radial quando as barras partem de uma barra transversal localizada abaixo do cavalete.

Barras: Podem apresentar a seção transversal semicircular, quadrada, retangular, triangular e retangular alta com desbastes nas extremidades [38. Com relação ao perfil da barra como um todo, pode ser em forma de arco, reta com entalhes nas extremidades ou ainda, reta com entalhes ou furos na extremidades e no corpo.

\footnotetext{
${ }^{4}$ Embora não seja uma característica própria dos leques, é conveniente mencionar que alguns luthiers costumam utilizar um reforço colado internamente no tampo, imediatamente abaixo do cavalete, o qual recebe as denominações de contracavalete ou língua.
}

\subsubsection{Características de alguns leques históricos}

Características dos leques dos construtores clássicos conforme descritos por Courtnall [29] e Friederich [38]. A representação esquemática destes leques é mostrada na figura 3 na forma de uma linha do tempo.

Leque Transversal: Nos violões primitivos, o tampo era reforçado com algumas barras apenas no sentido transversal, adaptadas dos sistemas comumente utilizados em alaúdes, estas barras eram dispostas em linha reta ou ligeiramente anguladas. Esse sistema não é mais utilizado.

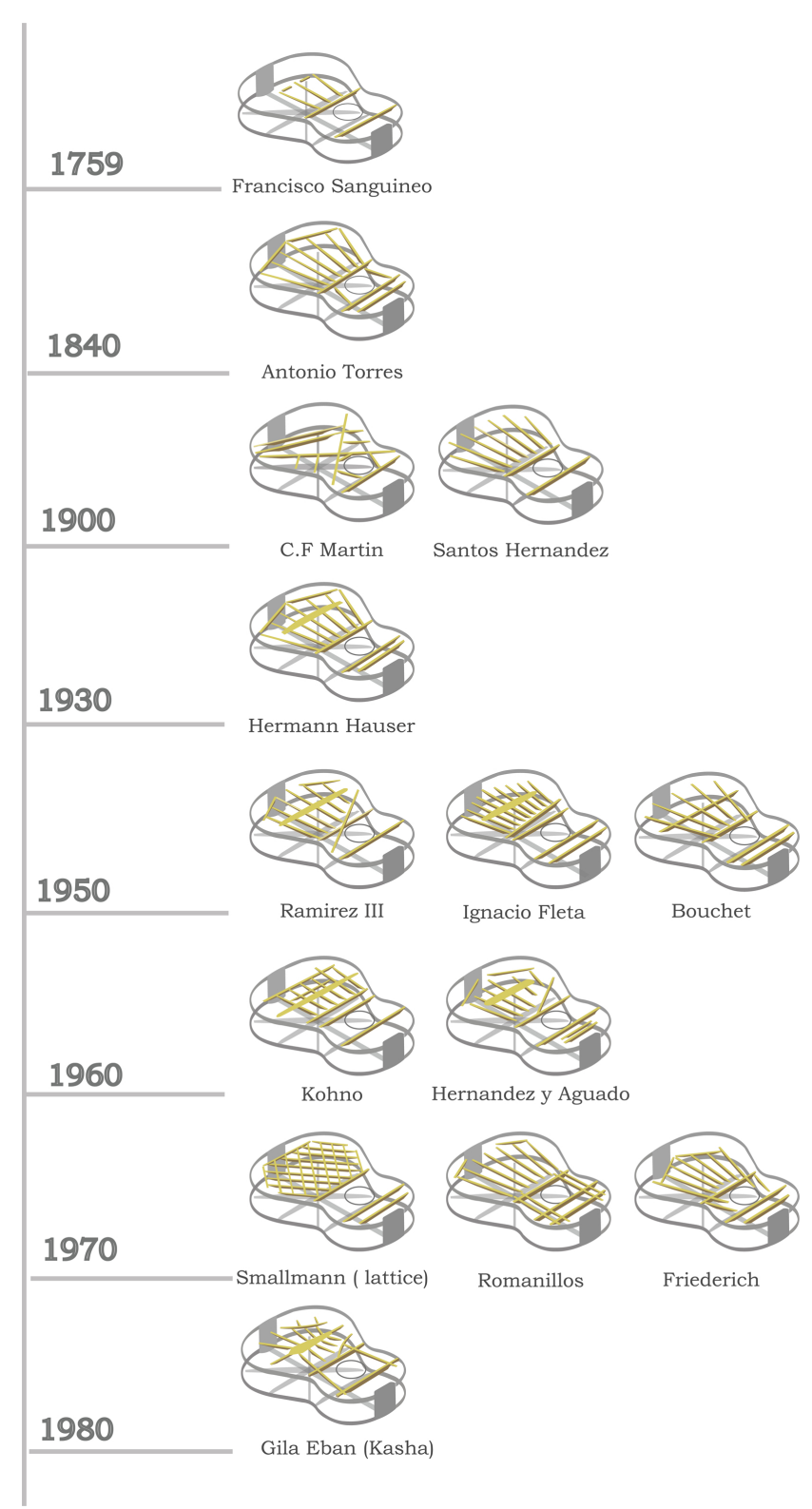

Figura 3: Linha do tempo dos principais leques harmônicos de violão iniciando em 1759 com o leque criado por Francisco Sanguineo até os anos $1980 \mathrm{com}$ a variante do leque de Michael Kasha criada pela luthière Gila Eban. As características de cada leque encontram-se discutidas no texto. 
Francisco Sanguineo: de Francisco Sanguineo (c. 1750), luthier. Leque simétrico, com 3 barras longitudinais.

Leque em X: de Christian Friedrich Martin (1796 1873), luthier. Leque assimétrico em forma de $\mathrm{X}$ desenvolvido por volta da mesma época em que Torres criava o seu sistema. Surgiu décadas antes das cordas de aço, porém por se adequar as necessidades dos violões de aço, que suportam uma maior tensão, é mais utilizado nestes instrumentos. Possui contracavalete.

Torres: de Antonio de Torres Jurado (1817 - 1892), luthier. Leque simétrico, fechado, com 7 barras longitudinais. Nos primeiros violões as barras tinham a seção transversal no formato triangular, depois passaram a ser arredondadas.

Hernandez: de Santos Hernandez (1874 - 1943), luthier. Leque simétrico, aberto, com 7 barras longitudinais.

Hauser: de Hermann Hauser I (1882 - 1952), luthier. Leque simétrico, fechado, com 7 barras longitudinais. Possui contracavalete.

Fleta: de Ignacio Fleta (1897 - 1977), luthier. Leque assimétrico, fechado, com 9 barras longitudinais, 2 barras centrais, 1 barra em $90^{\circ}$ e, 1 barra inclinada. Tampo mais espesso na área do cavalete, possui contracavalete.

Bouchet: de Robert Bouchet (1898 - 1986), luthier. Leque dissimétrico, aberto, com 5 barras longitudinais, 1 barra transversal na área do cavalete, 1 barra central com aberturas que permitem que as barras longitudinais se estendam até o reforço da boca. Apresenta tampo curvo. Ramirez: de José Ramírez III (1922 - 1995), luthier. Leque assimétrico, fechado, com 6 barras longitudinais, sendo 1 barra central, 3 no lado das cordas graves e duas no lado das agudas, 1 barra central em $90^{\circ}$ e 1 barra inclinada. Possui contracavalete.

Hernández y Aguado: de Manuel Hernández (1895 1975), luthier e Victoriano Aguado (1897 - 1982), luthier. Leque assimétrico, fechado, com 6 barras longitudinais, meia barra diagonal no lado das cordas agudas. Possui contracavalete.

Kohno: de Masaru Kohno (1926 - 1998), luthier. Leque assimétrico, fechado, 6 barras longitudinais, 3 do lado agudo, 1 central e 2 do lado grave. Possui 5 barras transversais e também contracavalete.

Lattice: de Greg Smallman (19?? - ), luthier. Leque simétrico, possui barras reforçadas com fibra de carbono, proporcionando a redução da espessura do tampo.

Kasha: de Michael Kasha, (1920 - 2013), físico-químico. Foi desenvolvido em colaboração com Richard L. Schneider (1936 - 1997), luthier. Leque assimétrico, radial, 1 barra transversal na área do cavalete, barras curvas. Possui um número muito maior de barras do que sistemas derivados de Torres, sendo estas mais curtas. Formato especial de cavalete adaptado ao leque.

Friederich: de Daniel Friederich (1932 - ), luthier. Leque simétrico, fechado, com 7 barras longitudinais. Possui uma barra transversal na região do cavalete.

Romanillos: de Jose Romanillos (1932 - ), luthier. Leque simétrico, parcialmente aberto, com 7 barras lon- gitudinais e 4 barras menores ao lado da boca. Barras transversais com aberturas que permitem a passagem das barras longitudinais.

\section{Aplicando Física no violão}

\subsection{O ressonador de Helmholtz no violão}

Um objeto com um volume interno $V_{0}$, um gargalo de comprimento $L$ e, uma abertura cuja área da seção transversal é $S$ é um ressonador de Helmholtz genérico. O violão pode ser em primeira aproximação considerado um ressonador de Helmholtz, cujas quantidades análogas são o volume interno do seu corpo, a espessura do tampo na região da sua boca e, a área da boca, respectivamente.

Ao se deslocar uma fatia de ar do tubo de uma quantidade $x$, o volume do ar que estava dentro diminui, sendo agora $V=V_{0}-S x$ e, a pressão interna aumenta, sendo $P_{i}=P_{0}+P$, onde $P_{0}$ é o valor da pressão atmosférica e $P$ o aumento da pressão devido ao deslocamento $x$. Relacionando a pressão e o volume com as suas respectivas variações através da razão dos calores específicos $\gamma$, chega-se a

$$
\frac{P}{P_{i}}=-\gamma \frac{\Delta V}{V_{0}},
$$

fazendo $\Delta V=S x$, uma vez que a variação do volume é dada pela área da seção transversal do gargalo multiplicada pelo deslocamento da fatia de ar e, considerando a pressão interna inicial igual a pressão atmosférica, podese rearranjar a equação (3) na seguinte forma

$$
\frac{P}{P_{0}}=-\gamma \frac{S x}{V_{0}} \text {. }
$$

A massa da fatia de ar deslocada é dada por $m=\rho S L$, sendo $\rho$ a densidade do ar e, considerando a relação entre força, pressão e área $F=P S$, de forma que a segunda lei de Newton para o seu movimento passa a ser

$$
\frac{d^{2} x(t)}{d t}=\frac{P S}{\rho S L}
$$

Da equação 4 , tem-se $P S=-\frac{\gamma P_{0} S^{2} x}{V_{0}}$, o que substituido em (5) leva a

$$
\frac{d^{2} x(t)}{d t^{2}}=-\frac{\gamma P_{0} S^{2}}{V_{0} \rho S L} x(t)=-\frac{\gamma P_{0} S}{V_{0} \rho L} x(t) .
$$

Introduzindo a frequência angular $\omega=2 \pi f=\sqrt{\frac{\gamma P_{0} S}{V_{0} \rho L}}$ tem-se a equação diferencial para o movimento $x(t)$ da fatia de ar, a qual possui uma forma simples, dada por

$$
\frac{d^{2} x(t)}{d t^{2}}+\omega^{2} x(t)=0
$$

cujo conjunto de soluções 41 pode ser expresso como uma função oscilante com amplitude $A_{n}$, que possui uma 
fase $\phi_{n}$, sendo $n=1,2,3, \ldots$, como segue

$x(t)=\sum_{n=1}^{\infty} A_{n} \cos \left(n \omega t+\phi_{n}\right)=\sum_{n=1}^{\infty} A_{n} \cos \left(2 \pi n f t+\phi_{n}\right)$,

sendo a frequência fundamental deste sistema dada por $f=\frac{1}{2 \pi} \sqrt{\frac{\gamma P_{0} S}{V \rho L}}$, a qual pode ser escrita em termos da velocidade de propagação do som, $c=\sqrt{\frac{\gamma P_{0}}{\rho}}$, como

$$
f=\frac{c}{2 \pi} \sqrt{\frac{S}{V_{0} L}} .
$$

Aplicando esta modelagem a um violão, modelo Torres por exemplo, pode-se obter o valor da frequência do ressonador de Helmholtz formado pelo ar contido em seu interior. Como tamanho do gargalo, utiliza-se a espessura do tampo na região da boca do violão, cujo valor é $L=$ $0,5 \mathrm{~cm}$. A área da boca, que possui raio $(R)$ de $4,5 \mathrm{~cm}$, é de $S=63,62 \mathrm{~cm}^{2}$, equivale a área da abertura.

Para determinar o volume do violão foi utilizada a seguinte abordagem, desenhou-se o contorno em uma folha de papel milimetrado de densidade superficial $\rho_{s}$ (comumente chamada de gramatura) $63 \mathrm{~g} / \mathrm{m}^{2}$, recortouse o contorno obtido, o qual resultou em massa $m$ de 9,32 g. A partir destes dados, a área é dada por $S=\frac{m}{\rho}$, cujo resultado numérico é $S=1480 \mathrm{~cm}^{2}$. Multiplicando $S$ pelo valor médio da altura do corpo, que é $9,5 \mathrm{~cm}$, obtém-se um volume de $V=14.060 \mathrm{~cm}^{3}$ ou, aproximadamente 14 litros.

Se a eq. (9) for utilizada considerando a velocidade do som como $34000 \mathrm{~cm} / \mathrm{s}$, a frequência desta ressonância de Helmholtz, também chamada de Air cavity mode $A_{0}$ (em inglês) [34], é de $f=514 \mathrm{~Hz}$, o que está bastante acima do que se verifica experimentalmente, que geralmente fica entre $120 \mathrm{~Hz}$ e $130 \mathrm{~Hz}$. Pode-se incluir na eq. (9) a correção proposta por Wolf [33], de que o comprimento do gargalo na eq. (9) passa de $L \rightarrow(L+1,7 R)$, de forma que a frequência fundamental passa a ser $f=129 \mathrm{~Hz}$. Esta correção empírica advém do fato de o gargalo ser finito e, também da variação do volume interno do corpo do violão devido a sua estrutura flexível que apresenta modos de vibração próprios, os quais se acoplam ao ressonador de Helmholtz afetando suas frequências características.

\section{Do violão para a guitarra elétrica}

\subsection{Desenvolvimento dos captadores magnéticos}

Uma das primeiras tentativas de "amplificação" 5 do som de instrumentos de corda foi a de Augustus Stroh [42], que em 1900 usou no violino um sistema semelhante ao do gramofone 43], figura 4. O cavalete do instrumento

\footnotetext{
${ }^{5}$ Para que haja amplificação de fato é preciso injetar energia no sistema, aqui o termo é utilizado para designar uma melhor projeção do som, de modo que este seja percebido com maior intensidade por estar sendo direcionado.
}

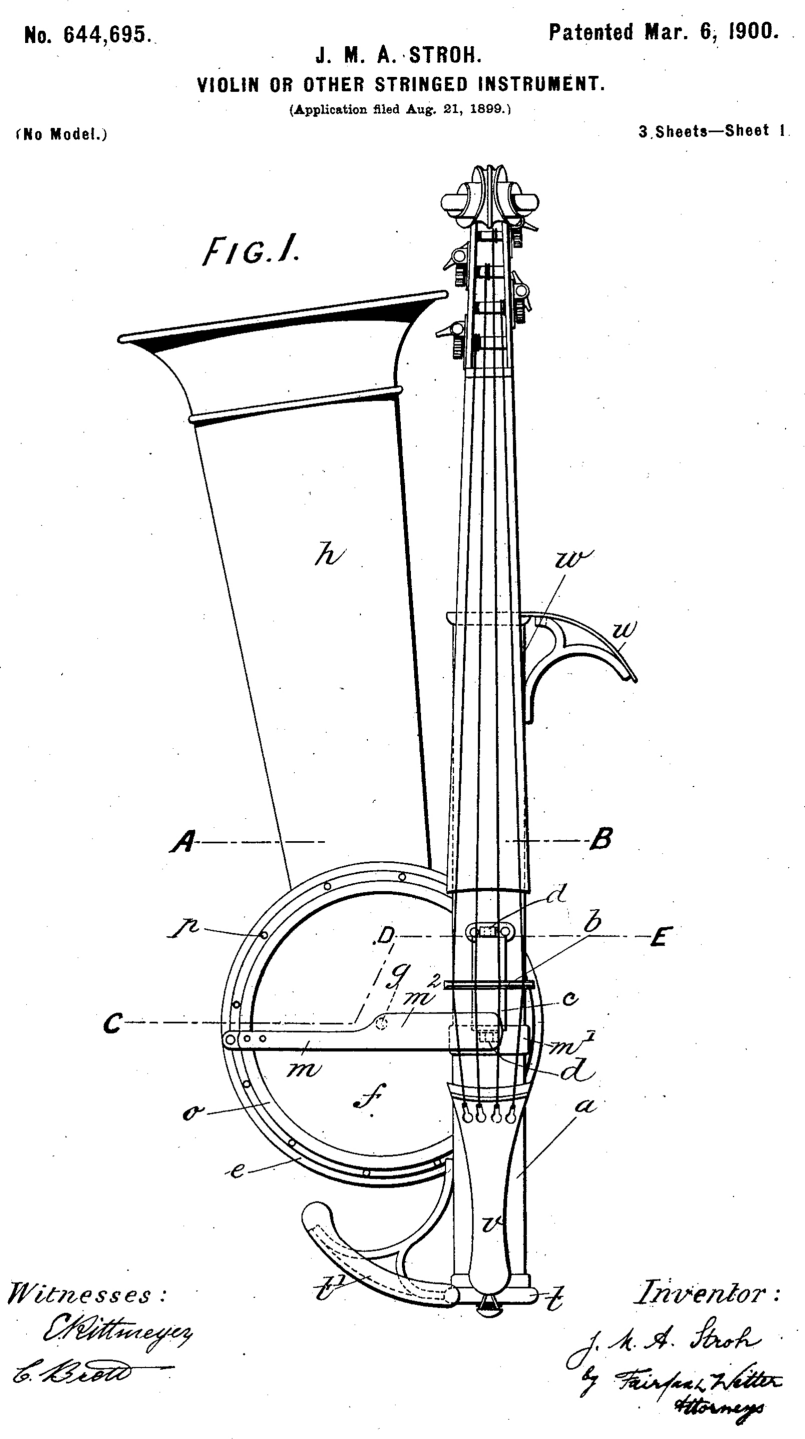

Figura 4: Desenho da patente № 644,695 do violino criado por J. M. A. Stroh [43 em 1900. As partes indicadas com letras latinas minúsculas são as responsáveis pela transmissão do som da corda, passando pelo cavalete e pelo diafragma até a emissão pela corneta, denotada por $h$.

excita uma membrana que produz o som, e é projetado por uma corneta. Esse sistema apesar de ter sido mais popular em violinos foi usado em outros instrumentos da mesma família e, até mesmo chegou a violões e bandolins.

Antes da invenção dos microfones e do sistema de gravação elétrico, a gravação de sons era mecânica. A música era tocada próxima a uma corneta que possuía uma membrana flexível, na qual estava presa uma agulha que imprimia as vibrações produzidas pelo som em um disco de cera [42]. Esse método limitava os sons que podiam ser registrados entre $350 \mathrm{~Hz}$ até $3000 \mathrm{~Hz}$. Os instrumentos de Stroh foram amplamente usados na 
indústria fonográfica na primeira metade do séc. XX, uma vez que produziam som direcional, facilitando o processo de gravação mecânica, porém tornaram-se obsoletos junto com o sistema de gravação mecânica quando a gravação elétrica foi inventada.

No começo do séc. XX nos Estados Unidos, o violão já estava consolidado no meio musical, com as guitarras archtop e os violões de cordas de aço. Porém, na composição das bandas de salão da época esses instrumentos não eram considerados muito importantes. Em meio a instrumentos de sopro, de arco, o piano e a percussão, seu som era quase inaudível [44]. Outros instrumentos de corda como o banjo e o bandolim conseguiam se sobressair melhor nesse contexto, sendo usados para melodias e o violão se restringia à parte rítmica.

Assim, naquele contexto, provavelmente só se ouvia o violão estando próximo ao palco ou em momentos em que o instrumento fazia solos e a banda diminuía sua dinâmica para que o solo pudesse ser escutado. Tentando resolver esse problema surgiram algumas propostas para a melhoria da projeção/irradiação sonora do instrumento. Uma das primeiras soluções foi a criação dos violões resonators 45 47], que possuíam cones que irradiavam som a partir da vibração vinda direto do cavalete, de maneira similar a um gramofone, cujos primeiros exemplares foram produzidos em 1927 44] em uma colaboração de George Beauchamp, Jonh Depyera e Adolph Rickenbacker.

Dado o problema exposto e a baixa eficiência dos sistemas mecânicos de "amplificação", surgiu a necessidade de que a abordagem adotada mudasse. Nisso surge o conceito de captador magnético, o qual é um transdutor, ou seja, um elemento que converte um tipo de sinal em outro tipo de sinal. No caso dos instrumentos de corda como o violão, a guitarra e o baixo elétrico, transformam parte da vibração da corda do instrumento em um sinal elétrico 48. Dentre as primeiras tentativas de captação 30 usando a indução magnética encontra-se o captador horseshoe, apresentado em um instrumento criado por Rickenbacker, conhecido como frying pan 44 por possuir uma certa semelhança a uma frigideira.

Como o captador geralmente era preso ao tampo de um instrumento acústico, um dos lugares com a maior amplitude de movimento da vibração do instrumento, consequentemente vibrava junto ao tampo, criando assim uma frequência aguda, que era amplificada pelo alto falante e alimentava a vibração do corpo, gerando o que é conhecido por microfonia acústica, problema que foi resolvido mais tarde com a utilização de um corpo sólido. Apenas no final da década de 1940 49, primeira guitarra de corpo sólido foi colocada no mercado por Leo Fender, a Broadcaster, que depois mudou seu nome para Telecaster, assim chegando aos modelos de guitarras conhecidos atualmente.

\subsection{Princípios de funcionamento}

O conceito mais simples de um captador magnético consiste de um ou mais ímãs com uma bobina formada por $N$ espiras enroladas ao seu redor. No caso do captador da guitarra elétrica Telecaster [50], são seis pólos de alnico (liga metálica composta primariamente por $\mathrm{Al}, \mathrm{Ni}$ e $\mathrm{Co}$ ) e uma bobina com cerca de 7800 a 9000 espiras de fio esmaltado, geralmente de bitola ${ }^{6}$ AWG 42. Próximo a estes, está uma corda de material ferromagnético, que é magnetizada pela presença do ímã. Quando a corda é colocada em movimento, passa a perturbar o campo magnético nas proximidades da bobina, gerando nessa uma corrente elétrica induzida.

O fluxo magnético 52,53 através de uma espira do captador, de área $S$, é definido como

$$
\Phi(t)=\int_{S} \vec{B}(t) \cdot d \vec{S}=\int_{S} \vec{B}(t) \cdot \vec{n} d S,
$$

onde $\vec{B}(t)$ é o campo magnético que passa através da espira, $\vec{n}$ é o vetor normal à área da espira. Sem perda de generalidade, adota-se aqui a área invariável e, o campo magnético dependente do tempo, sendo esta a situação que ocorre com o captador magnético. Tendo uma espira resistência elétrica $R$, a corrente elétrica $i(t)$ devido a diferença de potencial induzida $U=-\frac{d \Phi(t)}{d t}$, será dada pela lei de Faraday para $N$ espiras escrita como

$$
i(t)=-N \frac{1}{R} \frac{d \Phi(t)}{d t} .
$$

A corrente alternada $i(t)$ produzida pelo captador magnético, com a mesma frequência da oscilação da corda, passará pelos componentes do circuito do instrumento (como o controle de intensidade ou "volume" e o controle do tonalidade ou "tone") antes de ser enviada para amplificação de fato e, posteriormente para uma caixa de som. O sinal de menos deve-se a lei de Lenz, segundo a qual o sentido da corrente induzida é aquele que tende a se opor à variação do fluxo através da espira [54].

Antes de passar para os próximos desenvolvimentos, é interessante discutir como a arquitetura de um captador afeta $\Phi(t)$ e consequentemente o resultado sonoro final de um instrumento. Como a integração é feita sobre a superfície do contorno $C$ da espira, diferentes formas de enrolamento das espiras que formam a bobina do captador resultam em diferentes contribuições quando da realização da integração, levando assim a um $\Phi(t)$ diferente para um mesmo ímã e uma mesma corda. Para uma mesma corda e um mesmo enrolamento de bobina, diferentes ímãs levam a diferentes magnetizações da corda e, consequentemente, diferentes variações do campo magnético $\vec{B}(t)$, com diferentes valores de $\Phi(t)$, também alterando o resultado final. Cabe ainda salientar

\footnotetext{
$\overline{{ }^{6} \text { American Wire Gauge }[51]}$ é um padrão americano para a medida do diâmetro de fios, de forma que quanto maior o número que acompanha a sigla, menor o diâmetro. AWG 42 corresponde a o diâmentro de $0,064 \mathrm{~mm}$.
} 
que se o ímã tiver um campo magnético muito intenso, pode atenuar o movimento da corda, fazendo com que vibre por menos tempo depois de tocada, diminuindo o chamado sustain. E ainda, diferentes cordas, para um mesmo captador podem perturbar o campo magnético $\vec{B}(t)$ de maneiras distintas, afetando o som do instrumento.

A autoindutância $L$, segundo [55], é dada pela razão entre a força eletromotriz induzida $\epsilon$ e a variação temporal da corrente elétrica que percorre o indutor, tal que

$$
\epsilon=-L \frac{d I}{d t}
$$

sendo $L$ a propriedade que traz a informação sobre as características inerciais do circuito [53], sendo a sua unidade o henry $(\mathrm{H})$. Podendo ser tanto a auto-indutância, que é o valor da indutância de um componente ou do circuito do qual este faz parte ou, indutância mútua quando existem dois ou mais elementos que influenciam um ao outro em um circuito.

Como os indutores não são ideais e possuem resistência interna, uma descrição mais próxima da realidade implica em considerar um indutor real como sendo a combinação de um resistor $(R)$ associado em série com o indutor $(L)$. Desta forma, no caso de um captador de guitarra, o ideal seria classificá-lo através da sua auto-indutância porém, o que ocorre na prática, é que mesmo fabricantes utilizam o valor da resistência nominal do captador e não de sua auto-indutância. De maneira geral, a resistência interna de um captador, medida em corrente contínua, pode variar de $5 \mathrm{k} \Omega$ a $10 \mathrm{k} \Omega$ conforme a arquitetura do mesmo, já a indutância, apresenta valores que vão de $1 \mathrm{H}$ a $10 \mathrm{H} 56$. Embora os conceitos sejam distintos, existe uma certa coerência, uma vez que um captador vai ter sua resistência $(R)$ dada por

$$
R=\rho \frac{\ell}{A},
$$

onde $\ell$ é o comprimento do fio, e $A$ é a área da seção transversal do condutor. Desta maneira, com o aumento do número de voltas da bobina no captador, ocorre um aumento da resistência interna do captador. Para o caso da indutância, usando para fins de cálculos uma espira circular com $N$ voltas, a indutância pode ser calculada 53 . de maneira que esta passa a ser proporcional ao quadrado do número de voltas da bobina e à área da seção transversal. Desta forma, fazer referência ao captador pela sua resistência e não pelo valor da indutância é uma descrição qualitativa válida, uma vez que quanto maior o número de espiras, maior serão a resistência e a indutância. Esta analogia porém, nem sempre é boa, Jugmann $[56]$ exemplifica casos de captadores com alta resistência elétrica mas, indutância relativamente baixa.

\subsection{Alguns modelos de captador}

A forma mais simples que um captador magnético pode ter, é composta de apenas uma bobina, por isso chamado de single coil [46] em inglês, com um núcleo magnético. Este pode ter diversos tamanhos e formatos, sendo o mais comum com seis polos magnéticos 47, posicionados em baixo de cada uma das cordas, como mostrado na figura 5 Todos os ímãs tem a mesma orientação e o polo sul é virado pra cima, ficando mais próximo da corda. Os modelos mais conhecidos são os single coils das guitarras Stratocaster e Telecaster da marca Fender e o P-90 da marca Gibson.

Um problema comum em captadores é que eles funcionam como uma antena e sofrem interferência de campos magnéticos externos ao instrumento. Em sons diretos do instrumento e sem efeitos de $d r i v \emptyset^{7}$ ou boos ${ }^{8}$ a relação de sinal/ruído é boa, mas quando efeitos passam a estar presentes, esta relação já não é mais satisfatória devido ao destaque do ruído em relação ao sinal. Visando encontrar uma solução para esse problema, o captador humbucker foi criado por Seth Lover e Walter Fuller [57. na década de 1950. Este consiste em duas bobinas lado a lado, conforme a figura 5 , enroladas cada qual em um sentido (horário e anti-horário).

Essa montagem faz com que a corrente elétrica induzida nas diferentes bobinas por uma variação de campo magnético externo possua fases opostas, de maneira que

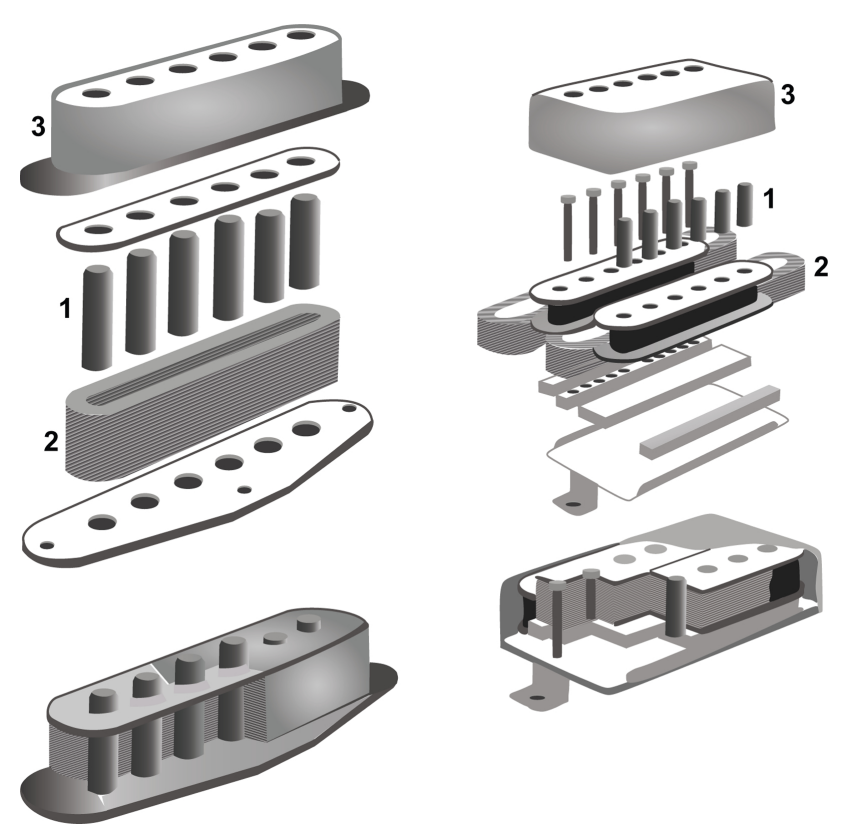

Figura 5: Visão explodida de um captador magnético do tipo single coil à esquerda e de um captador magnético do tipo humbucker à direita, ambas as figuras adaptadas da referência [47]. As partes identificadas na figura são: 1 ímãs, 2 bobina(s) e $\mathbf{3}$ capa. Toda a estrutura do captador é montada sobre uma base na sua parte inferior.

\footnotetext{
${ }^{7} \mathrm{O}$ aumento do ganho causa a distorção, que é a saturação do som, obtida pelo uso de amplificadores com volume no máximo, ou por dispositivos (pedais, pré amplificadores) que causam o clipping (ou ceifamento) do som quando ligados a cadeia de sinal.

${ }^{8} \mathrm{~A}$ amplificação de som ligado a cadeia de sinal, que tem como objetivo aumentar a intensidade sem causar o efeito de distorção, ou de realçar frequências específicas do sinal.
} 
a soma dos sinas de cada bobina seja muito próxima de zero. Para que o sinal produzido pelo movimento das cordas também não se anule, os ímãs de cada bobina são invertidos [55], ou seja, enquanto a parte superior (mais próxima das cordas) de todos os ímãs de uma bobina é polo norte na outra bobina, são todos polo sul, de maneira que o sinal resultante é mais intenso do que o sinal de uma bobina individual. O fato do humbucker possuir duas bobinas uma do lado da outra faz com os ímãs do captador produzam um campo magnético mais intenso e também mais extenso espacialmente [47] que os captadores de uma bobina, permitindo captar uma porção maior da corda vibrante.

Isso faz com que capte melhor as ondas de frequência mais baixa, pois possuem maior comprimento de onda, deixando assim com harmônicos graves mais intensos, gerando um som característico e distinto do som de um captador de uma bobina.

A existência de duas bobinas também permite que sejam exploradas as ligações entre elas, podendo ser ligadas em série ou em paralelo, interferindo de maneira distinta no comportamento do captador e no resultado sonoro final [56]. De maneira bastante simplificada, quando ligadas em série a resistência resultante será a soma das resistências individuais, resultando em um som mais intenso, caracterizado pela presença baixas frequências (sons graves), perda nas frequências altas (sons agudos) e, uma boa relação sinal/ruído. Já na ligação em paralelo, a resistência resultante é a metade da soma das resistências individuais de cada bobina, criando um som consideravelmente menos intenso, com maior presença de altas frequências (sons agudos), e uma pior relação sinal/ruído. Uma outra arquitetura possível é a do captador stacked humbucker, que são captadores com duas bobinas 'empilhadas', ou seja, uma em cima da outra [46, 47, 50]. A bobina situada na parte de cima - mais próxima das cordas - é a principal responsável pela captação e, a bobina que fica em baixo, cujo enrolamento e orientação dos polos dos ímas estão em sentido inverso a da superior, tem a finalidade de eliminar parte do ruído como em um captador humbucker.

\section{Conclusões}

Este artigo traz informações sobre aspectos gerais do violão, instrumento musical classificado como cordófono dedilhado. Após um breve histórico sobre sua origem, o violão foi discutido como um objeto, suas partes, as respectivas funções e materiais comumente utilizados. A parte estrutural envolvendo o leque harmônico foi descrita de maneira detalhada, tendo sido apresentados os principais modelos de leques já criados. Uma descrição mais matematizada do ressonador de Helmholtz que existe no corpo do violão leva à uma última seção, onde a transição do violão para a guitarra elétrica é tratada, assim como alguns aspectos gerais dos captadores.

\section{Agradecimentos}

Agradecemos ao Frederico M. Vorraber pelo auxílio com a medida do volume interno do corpo do violão e, ao luthier Lucas G. Schafhauser pela leitura crítica e revisão textual. À Élen Crocetti Pereira pela versão em inglês do resumo. Ao Ivan Dimidiuk pelo auxílio com a produção das figuras. Agradecemos à Universidade Federal do Paraná pelo apoio à realização deste trabalho, no âmbito do Programa Institucional de Iniciação Científica.

\section{Referências}

[1] T. Evans and M.A. Evans, Guitars From the Renaissance to Rock (Facts on File, New York, 1977).

[2] R. Hochstrasser and J. Saltiel, J. Phys. Chem. A 107, 3161 (2003).

[3] M. Kasha, Guitar Review 30, 3 (1968).

[4] I. Sloane, Classic Guitar Construction (Omnibus Press, Londres, 1976).

[5] A.B. de H. Ferreira (ed), Mini Aurélio: O Dicionário da Lingua Portuguesa (Editora Positivo, Curitiba, 2004), $7^{\mathrm{a}}$ ed.

[6] J. Tyler and P. Sparks, The Guitar and its Music From the Renaissance to the Classical Era (Oxford University Press, New York, 2007).

[7] M. Boyd and J.J. Carreras (orgs), Music in Spain During the Eighteenth Century (Cambridge University Press, Cambridge, 1998).

[8] J.L. Romanillos, Antonio de Torres, Guitar Maker His Life and Work (Element Books, Shaftesbury, 1987).

[9] S.M. Alfonso, O Violão da Marginalidade à Academia: Trajetória de Jodacil Damaceno (EDUFU, Uberlândia, 2009).

[10] G. Bartolini, Violão o Instrumento da Alma Brasileira (Editora Prismas, Curitiba, 2015).

[11] M. Taborda, Violão e Identidade Nacional (Editora Civilização Brasileira, Rio de Janeiro, 2011).

[12] E.M. Santos, C. Molina e A.P.B. Tufaile, Rev. Bras. Ens. Fis. 35, 2507 (2013).

[13] A.L.M. de B. Coelho e A.M.M. Polyto, Physicae Organum 2, 1 (2016).

[14] D.D. de A. Moura e P.B. Neto, Física na Escola 12, 12 (2011).

[15] M.L.N. Grillo, L.R.P.L. Baptista, J.A. de A. Crespo, S.A. Moreira e L. das N. Vicente, in: II Simpósio Nacional de Ensino de Ciência e Tecnologia, Artigo 82, (2010).

[16] M.L. Grillo e L.R. Perez (orgs), A Física na Música (EdUERJ, Rio de Janeiro, 2013).

[17] E.M. von Hornbostel and C. Sachs, Galpin Society Journal 14, 3 (1961).

[18] L. Henrique, Acústica Musical (Calouste Gulbenkian, Lisboa, 2011).

[19] D. Weissman, Guitar Tunning (Taylor and Francis Group, New York, 2006).

[20] H.E. White and D.H. White, Physics and Music (Dover, Mineola, 2014).

[21] H. Pleijsier, Prewar Instrument Styles (Centerstream, Milwaukee, 2008).

[22] W. Martin, Guitar Owner Manual (John Muir, Santa Fe, 1983). 
[23] H.F. Olson, Music, Physics and Egineering (Dover, New York, 1967), $2^{\mathrm{a}}$ ed.

[24] A. Willis, Step-By-Step Guitar Making (Guild of Master Craftsman, Lewes, 2010).

[25] G. Schwesinger, How to Build Your Own Guitar (1st Books, Fairfield, 2002).

[26] M.H. de Souza, Madeiras Utilizadas para a Fabricação de Instrumentos Musicais (Ministério do Meio Ambiente, Brasília, 2009).

[27] L. Sandberg, The Acoustic Guitar (A Cappella Books, Chicago, 2000).

[28] B. Med, Teoria da Música (Musimed, Brasília, 1996), $4^{\mathrm{a}}$ ed.

[29] R. Courtnall, Making Master Guitars (New Era Printing, Hong Kong, 1993).

[30] T. Gerken, M. Simmons, F. Ford and R. Johnston Acoustic Guitar: An Historical Look at the Composition, Construction, and Evolution of one of the World's Most Beloved Instruments (Hal Leonard, Milwaukee, 2003).

[31] R.H. Siminoff, Siminoff's Luthiers Glossary (Hal Leonard, New York, 2008).

[32] L. Robinson, The Art of Inlay (Backbeat Books, Milwawaukee, 2005).

[33] Helmholtz Resonance, disponível em https: //newt.phys.unsw.edu.au/jw/Helmholtz.html acesso em $22 / 3 / 2017$.

[34] N.H. Fletcher and T.D. Rossing, The Physics of Musical Instruments (Springer-Verlag, New York, 1991).

[35] A. Chaigne and J. Kergomard. Acoustique des Instruments de Musique (Springer, Paris, 2008).

[36] E. Jansson Acoustics for Violin an Guitar Makers (Edição do autor, Estocolmo, 2002), $4^{\mathrm{a}}$ ed.

[37] J. Meyer, in: Function, Construction and Quality of the Guitar, edited by E.V. Jasson (Royal Swedish Academy of Music, Estolcomo, 1983).

[38] D. Friederich, Acoustique et Instruments Anciens: Factures, Musique et Science (Société Francaise d'Acoustique, Paris, 1998).

[39] J. Jovicic and O. Jovicic, in: The Big Red Book of American Lutherie 1, 1985-1987 (Thomson-Shore, Dexter, 2000), p. 402-415.

[40] M. Kasha, Scientific Development of a New Classical Guitar (Kasha Model, Tallahassee, 1971.), $2^{\mathrm{a}}$ ed.

[41] T.C. Freitas and A. Laibida Jr., Physicæ8, 19 (2009).

[42] C.A. Clements, Experimental Musical Instruments 10, 8 (1995). Ibid. 11, 38 (1995).

[43] J.M.A. Stroh, Violin or Other Stringed Instrument US Patent 644,695 (1900).

[44] R.R. Smith, The History of Rickenbacker Guitar (Centerstream Publishing, Anaheim, 1987).

[45] R. Chapman, Guitar (Dorling Kindersley, Londres, 2005).

[46] W. Carter, The Gibson Electric Guitar Book (Backbeat Books, New York, 2007).

[47] D. Hunter, The Guitar Pickup Handbook: The Start of Your Sound (Backbeat Books, New York, 2008).

[48] F.T. Bann, in: Proc. IMAC-XXV Conference \& Exposition on Structural Dynamics 5 (Society for Experimental Mechanics, Orlando, 2007), p. 2122-2146.

[49] N. Freeth and C. Alexander, The Electric Guitar (Courage Books, Philadelphia, 1999).
[50] D. Hunter, The Guitar Sourcebook: How to Find the Sounds You Like (Backbeat Books, New York, 2006).

[51] S.A. Boggio e J.C. Ferreira, Revista Antenna Eletrônica 70, 46 (1973).

[52] J.B. Martins, A História da Eletricidade (Ciência Moderna, Rio de Janeiro, 2007).

[53] K.D. Machado, Teoria do Eletromagnetismo II (Editora UEPG, Ponta Grossa, 2002).

[54] H.M. Nussenzveig, Curso de Física Básica 3 (Editora Blücher, São Paulo, 1997).

[55] P.S. Guimarães, Minivocabulário de Física (Editora UFSM, Santa Maria, 2006).

[56] T. Jungmann, Theoretical and Practical Studies on the Behavior of Eletric Guitar Pick-Ups. Dissertação de Mestrado, Helsinki University of Technology, Helsinque, 1994, $107 \mathrm{p}$.

[57] D. Hunter, Bucking the Hum and Making History: Gibson's Hallowed Patent Applied for humbuckers, disponível em http://archive.gibson.com/en-us/ Lifestyle/ProductSpotlight/GearAndInstruments/ Bucking $\% 20$ the $\% 20 \mathrm{Hum} \% 20$ and $\% 20$ Making $\% 20 \mathrm{His} /$ acesso em 23/8/2016. 